\title{
Fatal aortic rupture during balloon dilatation of recoarctation
}

\author{
Seshadri Balaji, Rachel Oommen, Philip G Rees
}

\begin{abstract}
In an eight year old boy with a patch aortoplasty, the aorta ruptured during balloon angioplasty for recoarctation. At necropsy a $1.5 \mathrm{~cm}$ long, full thickness tear and a separate, smaller, intimal tear were found. Histological examination showed thinning of the elastic laminae of the aorta.

Angioplasty for recoarctation may be dangerous in patients with a patch aortoplasty.
\end{abstract}

Balloon angioplasty is now an accepted method for the relief of recoarctation of the aorta. $^{12}$ There are six reports of death after this procedure. ${ }^{12}$ Cooper et al, from our hospital, reported successful balloon angioplasty with no mortality in 46 patients. ${ }^{3}$ We report a case of fatal aortic rupture after balloon angioplasty by the same technique as reported by Cooper et al. ${ }^{3}$

\section{Case report}

We performed balloon angioplasty for recoarctation in an eight year old symptom free child. He had undergone resection and end to end anastomosis at the age of 12 days, followed by patch aortoplasty for recoarctation at the age of five months, and closure of ostium primum atrial septal defect when he was four years old. He had persistent upper limb hypertension controlled by enalapril, poor femoral pulses, and evidence of left ventricular hypertrophy on the electrocardiogram and the echocardiogram. Doppler examination of his descending aorta showed an instantaneous gradient of $36 \mathrm{~mm} \mathrm{Hg}$ with flow extension to diastole typical of a coarctation. At catheterisation a peak to peak gradient of $20 \mathrm{~mm} \mathrm{Hg}$ was found and angiography showed two indentations on the inner curve of the aorta just distal to the left subclavian artery (fig 1).

We used angiographic methods described elsewhere ${ }^{3}$ to measure the diameter $(14 \mathrm{~mm})$ of the aorta immediately proximal to the coarctation. Balloon dilatation was performed initially with a $15 \mathrm{~mm}$ diameter and $3 \mathrm{~cm}$ long balloon (Meditech). We did not use manometry to determine balloon pressure because we had found that it was usually not possible to overinflate a balloon to a diameter greater than its manufactured one. On the second inflation the balloon burst. Repeat angiography showed that the recoarctation was unchanged. A $12 \mathrm{~mm}$ diameter, $4 \mathrm{~cm}$ long balloon (Olbert Catheter System) was re-sited across the coarctation with the same guide wire and inflated twice. During the deflation phase after the second inflation there was sudden opacification of the upper lobe of the left lung, blood came from the endotracheal tube, and blood pressure fell. A full resuscitation procedure was instituted and an emergency left thoracotomy carried out; haemostasis was achieved with difficulty. Despite vigorous attempts at resuscitation the child deteriorated and he died 4 hours after the procedure.

At necropsy there was a longitudinal tear $(1.5 \mathrm{~cm})$ in the aorta adjacent to the patch. It extended through all layers (fig 2). The upper lobe of the left lung was wrapped around the aorta with dense adhesions. There was a

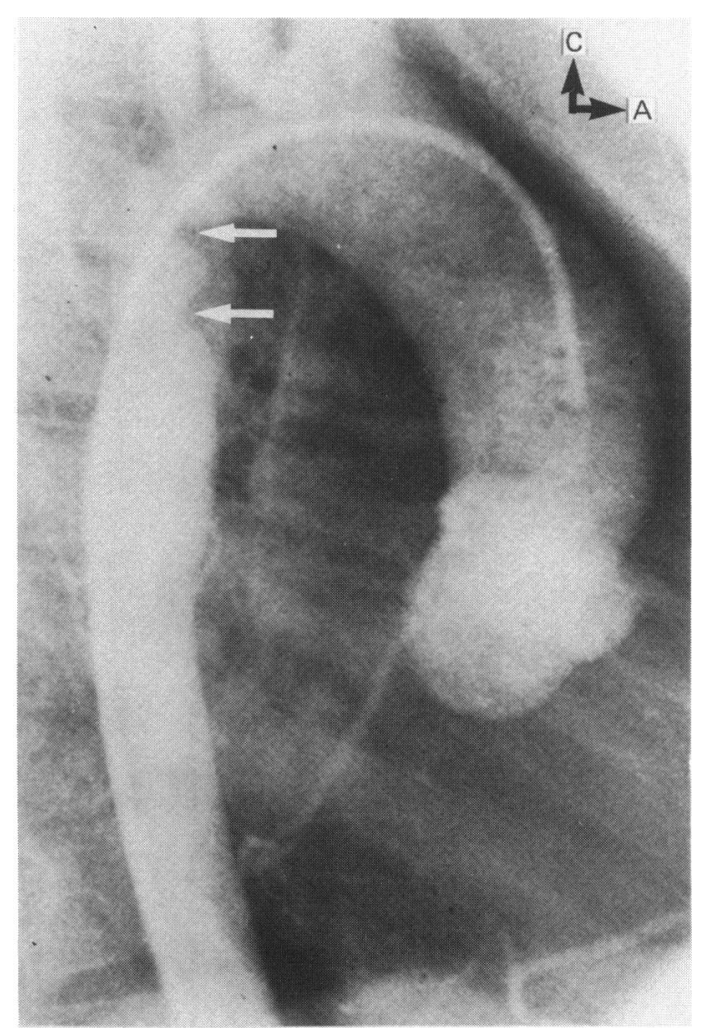

Figure 1 Lateral cineangiogram of the aorta showing two discrete areas of stenosis (arrows). A, anterior; $C$, cranial. 
Figure 2 Appearance of the aortic wall after death (seen from the intimal surface). There was a full thickness through the aortic wall $(A-B)$, and a separate intimal tear (C-D)

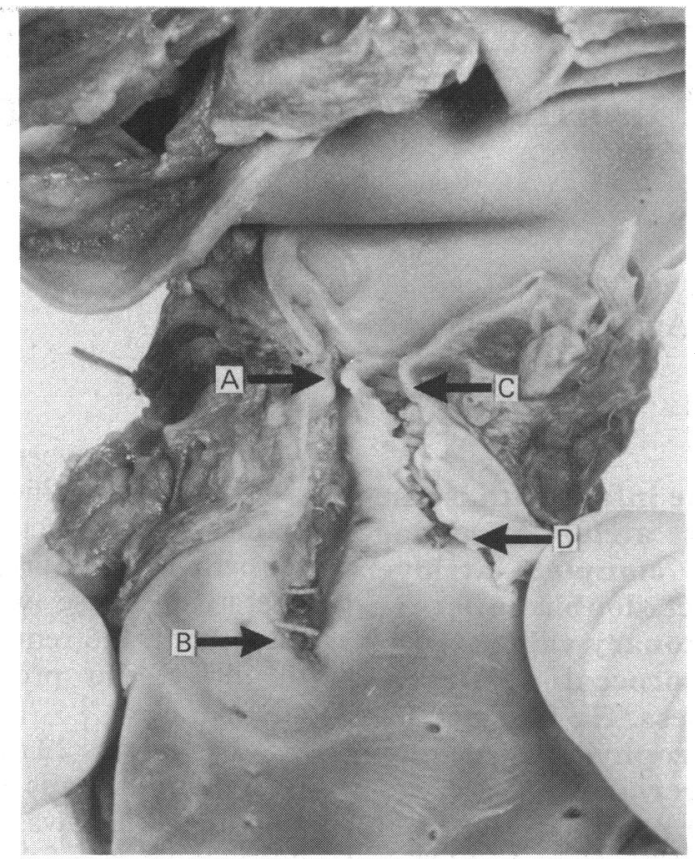

separate intimal tear $(0.5 \mathrm{~cm}$ long) opposite the patch (fig 2).

\section{Discussion}

Balloon angioplasty has been hailed as a major advance in the treatment of recoarctation of the aorta. ${ }^{4}$ Six deaths have been reported after this procedure. Kan et al reported one death that was thought to be due to a vagal event. ${ }^{1}$ Hellenbrand et al recently reported the results of the Valvuloplasty and Angioplasty of Congenital Anomalies (VACA) registry. There were five deaths in a group of 200 patients undergoing balloon angioplasty for recoarcta- tion. $^{2}$ Of these, only one was due to aortic rupture. Hellenbrand et al did not report the initial surgery undergone by this patient.

The Boston group (J E Lock, personal communication) have performed balloon angioplasty on 32 patients after patch aortoplasty with no complications. They have suggested to us that when the initial balloon burst it produced aortic damage because of the sudden release of shear forces and that the subsequent inflations enlarged the tear and resulted in rupture.

If the aorta ruptures we believe that the balloon should be reinflated across the ruptured segment and surgical repair started immediately. More experience of the effects of angioplasty is likely to identify specific subgroups in which balloon angioplasty is hazardous. We did not think that patch aortoplasty was a contraindication to balloon angioplasty and we had already achieved good results in four patients. ${ }^{3}$

Until more is known about the results of balloon angioplasty for aortic recoarctation we propose that this procedure should be avoided in patients with patch aortoplasty. We believe that further inflations should be avoided after a balloon has burst across an area where the vessel wall is likely to be thinned.

1 Kan JS, White RI Jr, Mitchell SE, Farmlett EJ, Donahoo JS, Gardner TJ. Treatment of restenosis of coarctation by JS, Gardner TJ. Treatment of restenosis of coarctation by 68:1087-94.

2 Hellenbrand WE, Allen HD, Golinko RJ, Hagler DJ, Lutin W, Kan J. Balloon angioplasty for aortic recoarctation Results of Valvuloplasty and Angioplasty of Congenital Anomalies registry. Am J Cardiol 1990;65:793-7.

3 Cooper SG, Sullivan ID, Wren C. Treatment of recoarctation: balloon dilatation angioplasty. J Am Coll Cardio 1989;14:413-9.

4 Huhta JC. Angioplasty for recoarctation. Editorial comment. J Am Coll Cardiol 1989;14:420-1. 